\title{
Avaliação do efeito da inclinação e umidade antecedente na qualidade e quantidade das parcelas escoadas, percoladas e armazenadas em telhado verde extensivo
}

\author{
The effect of slope and of antecedent soil moisture on \\ quality and quantity of stored, percolated and retained \\ fractions on extensive green roofs
}

\section{Rodrigo Braga Moruzzi \\ Cinthia Cristine de Moura \\ Ademir Pacelli Barbassa}

$\stackrel{\text { Resu }}{\nearrow}$ módulos em atenuar o escoamento superficial dire $(\Delta U)$. A capacidade dos món atenuar o escoamento superficial direto foi medida em termos do coeficiente de escoamento superficial experimental (Cexp.). A soma das parcelas escoadas e percoladas também foi verificada. Medidas de cor aparente e turbidez foram feitas nas parcelas escoadas e percoladas e os valores foram correlacionados para cada inclinação. Os resultados indicaram que para $i$ de $10 \%$ os menores valores de Cexp foram registrados (média de 1,01\% $\pm 0,7 \%$ ). Para os demais ( $i$ de 20 e $30 \%$ ) os valores de Cexp obtiveram média em torno de $35 \% \pm 15 \%$. A soma das parcelas escoadas e percoladas apresentam valores médios de $77 \%$ para a inclinação de $10 \%$ e de $80 \%$ para as demais. Os valores de $i$ e de $\Delta U$ obtiveram coeficiente de explicação de $87 \%$ para parcela armazenada e $81 \%$ para parcela escoada. Para parcelas percoladas a tendência inversa foi observada. As lâminas armazenadas foram da ordem de $11,6 \pm 1,4 \mathrm{~mm}$ para o módulo com $i$ de $10 \%$, de $10,0 \pm 1,2 \mathrm{~mm}$ para o módulo com $i$ de $20 \%$ e de $9,5 \pm 1,1 \mathrm{~mm}$ para o módulo com $i$ de $30 \%$. Os resultados indicaram que a inclinação e a umidade antecedente são decisivas tanto na redução do escoamento gerado quanto no transporte de material do telhado para o sistema de drenagem e ou aproveitamento subsequentes.

Palabras clave: Telhado verde. Técnica compensatória. Simulação de chuva.

\section{Abstract}

This study investigated the effect of slope and antecedent soil moisture on the

Rodrigo Braga Moruzzi Universidade Estadual Paulista Júlio de Mesquita Filho Rio Claro - SP - Brasil

Cinthia Cristine de Moura Universidade Estadual Paulista Júlio de Mesquita Filho Rio Claro - SP - Brasil

Ademir Pacelli Barbassa Universidade Federal de São Carlos São Carlos - SP - Brasil

Recebido em 27/08/13 Aceito em 01/05/14 water depth stored and percolated on extensive green roofs built in pilot scale. For this purpose, slopes of 10, 20 and 30\% were investigated. Moisture was measured before and after each test in order to determine the differential moisture $(\Delta U)$. The experimental runoff and percolated flow were analyzed by varying moisture and slope. Apparent color and turbidity were measured on runoff and percolated flow for each one of the modules. The results yielded that for the slopes of $10 \%$ the smaller values of runoff was obtained (average of 1,01\% $\pm 0,7 \%$ ). For the others slopes $(20 \%$ and $30 \%)$, the runoffs were around $35 \% \pm 15 \%$. The sum of runoff and percolated water results in $77 \%$ (average) for slope of $10 \%$ and $80 \%$ for $20 \%$ and $30 \%$. The slope and moisture have explained $87 \%$ of data for retained water and $81 \%$ for runoff. For percolated flow the inverse trend was observed. The retained water was 11,6 $\pm 1,4 \mathrm{~mm}$ for the module with $10 \%$ of slope, around

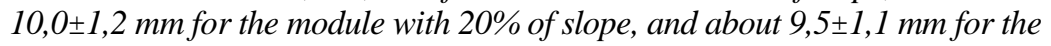
module with $30 \%$. The results pointed out that both slope and antecedent moisture are crucial for runoff reduction and for material transportation.

Keywords: Green roof. Compensatory technique. Rainfall simulation. 


\section{Introdução}

A tecnologia do telhado verde como um instrumento funcional para a civilização tem sua origem em diferentes regiões do mundo. $\mathrm{Na}$ Escandinávia, os telhados eram cobertos com uma mistura de terra e grama como forma de isolamento térmico. Abaixo dessa camada eram colocadas pesadas vigas de madeira intercaladas com cascas de árvores para a impermeabilização do telhado (RODRIGUEZ, 2006).

Entretanto, somente nos anos 1970 organizações privadas juntamente com universidades e centros de pesquisa começaram a desenvolver, na Alemanha, pesquisa sistemática com telhado verde e suas aplicações, introduzindo conceitos de hábitats ecológicos em áreas urbanas, e iniciando avaliações sobre o balanço energético e a drenagem.

A Associação Internacional de Telhado Verde (INTERNATIONAL..., 2010) divide o telhado verde em três categorias, distintas pela densidade de plantio, tipo de vegetação utilizada e capacidade estrutural do telhado, a saber:

(a) extensiva: para estruturas de telhados com pouca capacidade de carga e custos mais baixos, uma vez que exige pouca irrigação e adubação;

(b) semi-intensiva: maior capacidade de carga e custos medianos para a manutenção; e

(c) intensiva: alta capacidade de carga. Exige qualidade de manutenção, irrigação permanente e adubação constante (INTERNATIONAL..., 2010).

Entre os benefícios decorrentes da implantação de telhados verdes em áreas urbanas, o conforto térmico predial foi $\mathrm{o}$ mais mencionado $\mathrm{e}$ investigado. Vários trabalhos apontam redução significativa da temperatura no interior das edificações, quando comparado aos telhados tradicionais, mesmo em condições de baixa umidade, indicando que tais dispositivos não agem na refrigeração, mas sim no isolamento, diminuindo o fluxo de calor através do telhado (BARRIO, 1997; BASS et al., 2000; KOLB 2003; LAZZARIN; CASTELLOTTI; BUSATO, 2005).

Por meio do emprego de modelagem e simulação matemática, Barrio (1997) verificou que o telhado verde reduz significativamente o fluxo de calor em edificações. Lazzarin, Castellotti e Busato (2005) realizaram medições sistemáticas no Hospital de Vicenza-Itália. Os resultados foram avaliados por meio de modelo numérico, e concluiu-se que o telhado verde promoveu atenuação térmica de cerca de $60 \%$, quando comparado à cobertura convencional de telha cerâmica.
Sob o ponto de vista do meio ambiente urbano, o telhado verde também é mencionado na literatura como agente na modificação do microclima e na redução de poluentes atmosféricos. Nesse último quesito, resultados indicam a remoção de cerca de $1.700 \mathrm{~kg}$ de poluentes em 20 ha de telhado verde (YANG; YU; GONG, 2008).

Além dos atributos acima mencionados, o telhado verde é apontado como estrutura hidrologicamente eficiente, por auxiliar na retenção hídrica e na diminuição do pico de vazão de onda de cheia, quando comparado ao telhado convencional. No entanto, conforme mencionam alguns autores, seu efeito sobre as vazões geradas por precipitações em áreas urbanas é dependente da estrutura do telhado, especificamente quanto ao tipo de substrato e sua profundidade, inclinação, tipo de vegetação, etc. (MORAN; HUNT; JENNINGS, 2004; MENTENS; RAES; HERMY, 2005; KÖHLER et al., 2001).

Em decorrência de seu efeito hidrológico, o telhado verde está inserido no rol das técnicas que podem ser empregadas como estrutura de detenção e retenção de água de chuva, apresentando, no entanto, diferenças significativas em sua operação e manutenção quando comparado às demais técnicas compensatórias, tais como trincheiras, valas, poços de infiltração, pavimentos permeáveis e microrreservatórios. Suas principais diferenças decorrem das características inerentes a sua função primordial, a qual constitui a cobertura de prédios residenciais e comerciais.

No que se refere especificamente à função hidrológica do telhado verde, a inclinação da cobertura e a condição de umidade antecedente são fatores fundamentais para o desempenho hidrológico dele. Moran, Hunt e Jennings (2004) concluíram que o telhado verde reteve os primeiros $15 \mathrm{~mm}$ de precipitação monitorada e, em média, foi capaz de reter $63 \%$ da precipitação total. Quanto à vazão, os autores registraram redução do pico entre $78 \%$ e $87 \%$. Robertson (2005) estimou que a redução do escoamento superficial em telhado verde variou entre $40 \%$ e $80 \%$ em situações extremas de chuva e em condições normais respectivamente. Para precipitações com alturas pluviométricas superiores a $40 \mathrm{~mm}$, os autores obtiveram valores de coeficiente de escoamento superficial da ordem de 0,55. Teemusk e Mander (2007) apresentam que a retenção de água de chuva em telhado verde variou entre $70 \%$ e $90 \%$ no verão, e entre $25 \%$ e $40 \%$ no inverno.

Acrescentam-se a esses dados aqueles obtidos por Köhler et al. (2001), estudo em que se mostrou a 
diferença do volume retido nos telhados verdes de climas temperados (Berlim, Alemanha) e de climas tropicais (Rio de Janeiro, Brasil). Enquanto em Berlim a porcentagem de água retida variou de $50 \%$ a $75 \%$ da precipitação anual total, no Rio de Janeiro essa porcentagem foi de cerca de $65 \%$, devido principalmente à alta taxa de evapotranspiração. A variação da porcentagem de retenção merece especial atenção, segundo os autores, principalmente devido às condições do clima local, e também devido à influência do tipo e da densidade da vegetação instalada. Na Carolina do Norte, resultados de pesquisas indicam que o telhado verde pode reter cerca de $60 \%$ do total de chuva, alcançando picos de até $85 \%$ (MORAN; HUNT; JENNINGS, 2004). Estudos realizados na Michigan State University buscaram verificar o efeito da inclinação na retenção de chuvas. Os resultados indicaram que a capacidade de retenção do telhado verde diminuiu com o aumento da inclinação (GETTER; ROWE; ANDRESEN, 2007). Mentens et al. $\left(2005^{1}\right.$ apud FERREIRA; MORUZZI, 2007), reforçaram a ideia de que em épocas de clima quente a evapotranspiração é maior devido à maior capacidade de regeneração da retenção de água no substrato. Os autores quantificaram o volume de escoamento em uma camada de substrato com espessura entre $50 \mathrm{~mm}$ e $150 \mathrm{~mm}$, obtendo os seguintes valores de redução de escoamento:
(a) épocas quentes, $30 \%$;
(b) épocas frescas, $51 \%$; e
(c) épocas frias, $67 \%$.

As alturas pluviométricas e os tempos de recorrência não foram mencionados. Estudos conduzidos por Ohmuna Junior, Halasz e Mendiondo (2011), em telhado verde monitorado, indicam que, em relação ao total precipitado, $48 \%$ da parcela foi escoada em superfície. Por sua vez, Kolb (2003) encontrou um amortecimento dos picos de escoamento de $75 \%$ e concluiu, também, que a variação da inclinação pouco influencia no escoamento superficial: para uma inclinação de $2 \%$ a $8 \%$, os fatores de escoamento tiveram variação de somente 0,38 a 0,47 .

Lorenzini Neto et al. (2013) apresentam resultados de simulações hidrológicas em telhados verdes nos quais foram obtidos valores máximos de coeficiente de escoamento superficial da ordem de

${ }^{1}$ MENTENS, J. et al. Green Roofs as a Tool For Solving the Rainwater Runoff Problem in the Urbanized 21st Century. Department of Land Management, Laboratory for Forest, Nature \& Landscape Research. Leuven, Belgium, 2005. Disponível em: <http://www.elsevier.com/locate/ landurbanplan>. Acesso em: 28 fev. 2012.
$80 \%$, para diferentes localizações e condições de umidade antecedente.

Embora decisivos para o desempenho do telhado verde extensivo, poucos trabalhos avaliaram o efeito combinado da inclinação e da umidade antecedente nas parcelas escoadas, percoladas e armazenadas em telhado verde e suas relações com aspectos da qualidade da água que passa pelo telhado verde.

O presente trabalho apresenta uma avaliação da inclinação e da umidade e suas correlações, em instalação construída em escala piloto, constituída por três módulos independentes, submetidos às mesmas condições de ensaios. Adicionalmente, verificou-se a qualidade da água que passa pelo telhado, por meio de medições de cor aparente e turbidez.

\section{Materiais e métodos}

Os protótipos de $1 \mathrm{~m}^{2}$ de área em planta consistem em 3 reservatórios cortados a $18 \mathrm{~cm}$ a partir da base. As caixas foram perfuradas para a passagem de um dreno, constituído por um tubo de PVC perfurado com saída central, de forma a permitir a coleta da água percolada pelo substrato. Na mesma extremidade dreno, onde está localizado o tubo perfurado, foi feito o preenchimento com brita (900 mm de largura e $100 \mathrm{~mm}$ de altura), com a finalidade de servir de camada suporte do solo, evitando seu carreamento e facilitando a drenagem da água percolada. Sobre o restante da caixa foi adicionada uma camada de $130 \mathrm{~mm}$ de solo. Ainda na mesma extremidade (parte baixa da estrutura) e a $170 \mathrm{~mm}$ da base da caixa foi instalada a calha de coleta de água proveniente do escoamento superficial (Figura 1). Na saída do dreno de coleta de água percolada e da calha (coleta de água escoada superficialmente) foram posicionados recipientes de $20 \mathrm{~L}$ para a coleta dos efluentes.

O solo que serviu de substrato foi caracterizado segundo granulometria, textura, densidade aparente e real, e saturação, segundo a Embrapa (1997) e IAC (INSTITUTO..., 1986). A umidade gravimétrica percentual no solo foi medida em cada um dos protótipos antes do início dos ensaios e logo depois de cada bateria de ensaios. Para essa medição, foram coletadas duas amostras em porção média em relação à maior dimensão do telhado verde (comprimento), e foi utilizado o equipamento Medidor de Umidade Tipo Speedy da Solotest, modelo DNER-ME 052.

A herbácea escolhida para o plantio foi a Callisia repens, conhecida popularmente pelo nome dinheiro-em-penca, com base nos resultados de Portolano (2007), que determinou, por meio de 
experimentos, que essa é a melhor espécie para ser usada em telhados verdes no local da execução dos ensaios (Rio Claro, SP), devido às características climáticas locais. Os ensaios apresentados foram realizados após 6 meses do plantio.

A fim de avaliar o desempenho do telhado verde para diferentes inclinações, as caixas foram apoiadas sobre uma base fixa de $580 \mathrm{~mm}$ e sobre uma base móvel, que varia $10 \%, 20 \%$ e $30 \%$ em relação à altura da base fixa. Para que o volume d'água que irriga os módulos fosse controlado e fixado, as três caixas foram cobertas com telhas translúcidas de 2,44 m de comprimento e 1,1 $\mathrm{m}$ de largura.

Todos os ensaios foram avaliados por meio de teste estatístico (ANOVA) e apresentados com base nos intervalos de confiança calculados em $95 \%$ para a média.

\section{Análises quantitativas}

Para controle das precipitações foi desenvolvido um simulador de chuva constituído por microaspersores do tipo M50, instalados em tubulação. $\mathrm{O}$ arranjo dos aspersores do simulador de chuva foi adaptado a partir da proposta de Silva et al. (2009).
O melhor arranjo dos aspersores foi investigado variando-se diâmetros de tubos, número de aspersores e distância entre aspersores.

Foram realizados 14 ensaios, com $30 \mathrm{~min}$ de duração para cada configuração investigada, e houve variação no número e na distância dos aspersores no tubo e no número e na distância entre os tubos de PVC. Para assegurar a regularidade da vazão de entrada, as vazões foram aferidas antes e após cada ensaio, por meio da medida do volume em recipiente calibrado. Em cada condição investigada, avaliou-se o valor do coeficiente de dispersão espacial, por meio do Coeficiente de Uniformidade de Christiansen (CUC), conforme a Equação 1. Os testes para estimar o CUC consistiram em simular precipitações sobre uma plataforma de $1 \mathrm{~m}$ x $1 \mathrm{~m}$, com recipientes posicionados a cada $0,225 \mathrm{~m}$, dispostos conforme uma malha quadrada (Figura 2).

$$
C U C(\%)=100 .\left(1-\frac{S_{x}}{\bar{X}}\right)
$$

Em que $\bar{X}$ e $S_{x}$ representam a média e o desvio padrão dos volumes precipitados em todos os recipientes instalados na superfície de coleta respectivamente. $\mathrm{O}$ valor ideal da dispersão espacial ocorre quando não há desvio nas amostras, obtendo-se o valor de 1 (100\%).

Figura 1 - (a) Vista frontal com detalhe da folhagem logo após o plantio; (b) vista lateral dos módulos piloto de telhado verde imediatamente antes do plantio das mudas de Callisia repens; (c) vista frontal com calha de coleta e vegetação após 4 meses do plantio; e (d) corte esquemático das diferentes inclinações, correspondentes a $10 \%, 20 \%$ e $30 \%$, da esquerda para a direita, respectivamente

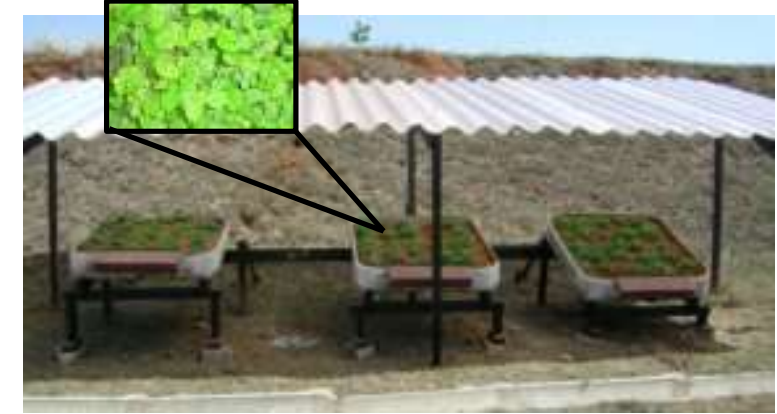

(a)

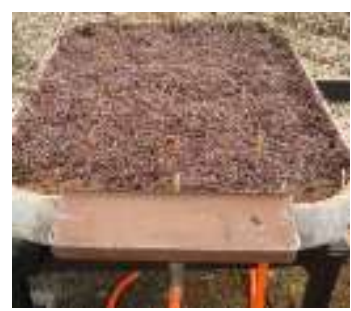

(c)

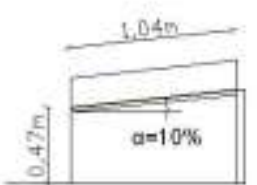

(d)

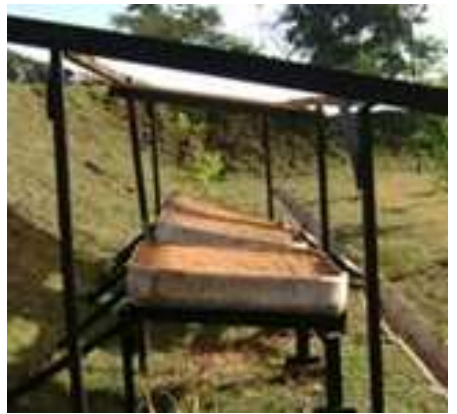

(b)

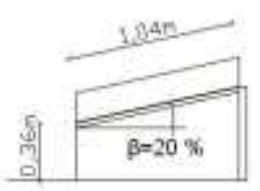

(d)

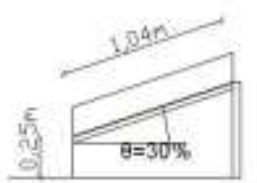

$9=30 \times$

62 Moruzzi, R. B.; Moura, C. C. de; Barbassa, A. P 
Para cada ensaio foi determinada a intensidade da chuva correspondente, conforme a Equação 2.

$I=\sum_{i=1}^{n} \frac{V b_{i}}{A b_{i} \cdot t}$

Em que:

I é a intensidade média (mm.min. $\left.{ }^{-1}\right)$;

$V b$ é o volume armazenado em cada recipiente (béquer) posicionado sobre a superfície de análise (L);

$A b$ é a área da seção transversal da boca do béquer $\left(\mathrm{m}^{2}\right)$;

$t$ é o tempo por ensaio; e

$n$ é o número de recipientes instalados na superfície.

Para a estimativa do período de retorno correspondente à intensidade média aplicada, utilizou-se a Equação 3, obtida por Moruzzi e Oliveira (2009), para a cidade de Rio Claro, SP.

$$
I=\frac{560,9 \cdot T^{0,141}}{(7,4+d)^{0,65}}
$$

Em que:

$I$ é a intensidade de chuva $\left(\mathrm{mm} \cdot \mathrm{h}^{-1}\right)$;

$T$ é o período de retorno (anos); e

$d$ é a duração da chuva (minutos).

Foram obtidas equações empíricas que relacionam parcelas escoadas e percoladas, por meio da regressão multilinear das variáveis independentes inclinação $(i)$ e umidade antecedente. As equações foram avaliadas por meio dos coeficientes de explicação $\mathrm{R}^{2}$ e $\mathrm{R}^{2}$-Ajustado. Os valores calculados e medidos e os resíduos padronizados foram plotados para avaliação do ajuste experimental.

O coeficiente de escoamento superficial experimental (Cехp.) e a soma das parcelas escoadas e percoladas foram determinados para cada inclinação $(i)$ e umidade antecedente, ou variação de umidade $(\Delta u)$, correspondente à diferença entre umidade inicial e final a cada bateria de ensaio. A umidade do solo foi determinada por meio do medidor de umidade do tipo Speedy, da Solotest, em amostragem composta de frações coletadas em diferentes posições na diagonal do telhado verde.

\section{Análises de cor aparente e turbidez da água}

As análises de cor aparente e turbidez foram realizadas nas dependências do Laboratório de Geoquímica Ambiental (Lagea), e no Laboratório de Tratamento e Reúso de Água e Efluentes (Latare), ambos pertencentes ao Departamento de Planejamento Territorial e Geoprocessamento da Unesp, Campus de Rio Claro. Os ensaios em laboratório foram conduzidos em amostras do percolado e do escoamento superficial direto (ESD), em cada um dos 3 protótipos investigados. Os ensaios para a determinação dos valores de cor aparente e turbidez foram obtidos por meio de espectrofotômetro HACH Dr-4000, com comprimento de onda de $455 \mathrm{~nm}$ e de turbidímetro, previamente calibrados no Latare, seguindo os procedimentos do Standard Methods $21^{\text {th }}$.

\section{Figura 2 - Arranjo dos recipientes para ensaios de uniformidade de distribuição por meio do teste do Coeficiente de Uniformidade de Christiansen (CUC)}

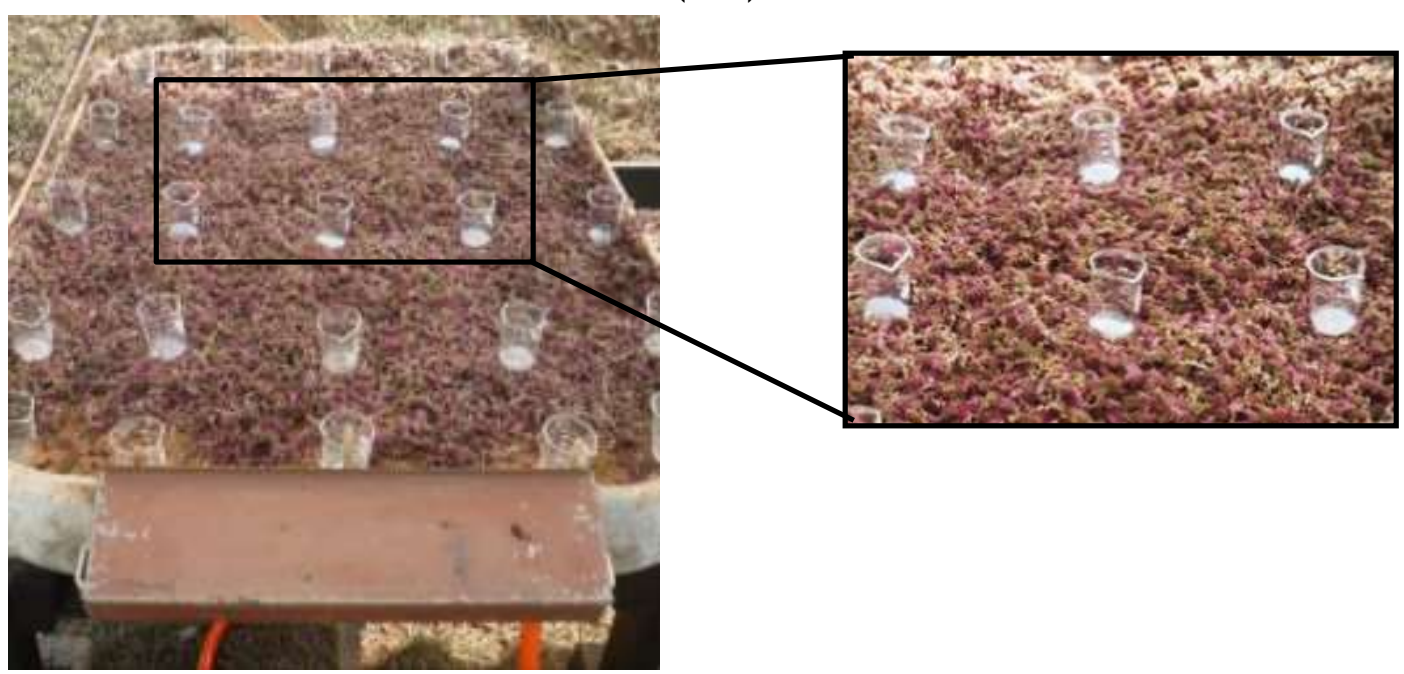


Os parâmetros turbidez e cor aparente monitorados foram correlacionados com as parcelas escoadas e percoladas. O material transportado por unidade de área do telhado verde foi avaliado indiretamente por meio do número $(N)$, definido pelo produto das parcelas escoadas e percoladas pelos parâmetros de qualidade, cor aparente (NC) e turbidez $(N T)$. Tais números representam indiretamente a carga de material presente nas parcelas hidrológicas do telhado verde.

Foi analisada a correlação entre a carga de material presente nas parcelas hidrológicas e os parâmetros $N T$ e $N C$.

\section{Resultados experimentais}

Os resultados da análise dos índices físicos do solo utilizado como substrato do telhado verde indicaram densidade do solo seco (aparente) de $2,32 \mathrm{~g} / \mathrm{cm}^{3}$ e densidade real de $2,59 \mathrm{~g} / \mathrm{cm}^{3}$. A porosidade medida foi de $10,42 \%$, e a saturação foi de aproximadamente $18,0 \%$. A granulometria indicou $38,8 \%$ de areia grossa, $36,2 \%$ de areia fina, $1,2 \%$ de silte e $23,6 \%$ de argila. A textura do solo foi classificada como franco argiloso arenoso, de acordo com o diagrama ternário de textura do IAC (INSTITUTO..., 1986). A taxa de infiltração média obtida foi da ordem de $5,45 \times 10^{-5} \mathrm{~m} / \mathrm{s}$.

Para definição do melhor arranjo dos aspersores foram realizados 14 ensaios, com $30 \mathrm{~min}$ de duração cada. Os 6 primeiros ensaios foram efetuados com o tubo de PVC de bitola $3 / 4$. O valor do $C U C$ para esses ensaios preliminares foi estimado a partir da Equação (1), cujo máximo valor foi de $38,6 \%$. Verificou-se que a pressão disponível dada pela posição do reservatório foi insuficiente.

Diante disso, a alternativa foi utilizar o ponto de abastecimento indireto alimentado por reservatório superior, próximo às instalações experimentais, com pressão de 10 m.c.a no ponto de utilização. Notou-se que os coeficientes obtidos foram mais altos quando comparados à situação anterior, sendo o valor de $56,2 \%$ o maior $C U C$ obtido. Assim, obteve-se a melhor configuração com 2 tubos de PVC de 3/4, com distância de $0,30 \mathrm{~m}$ da extremidade do telhado, cada um com 3 microaspersores espaçados em $0,15 \mathrm{~m}$ a partir da extremidade do tubo.

$\mathrm{Na}$ Tabela 1 apresentam-se os dados obtidos durante os ensaios para definir a melhor configuração dos microaspersores para o simulador de chuva.

Para a melhor condição de distribuição espacial, foram realizados ensaios visando estimar o desvio padrão, o intervalo de confiança de $95 \%$ e a média das intensidades das chuvas simuladas. A Tabela 2 apresenta os valores calculados obtidos a partir de cinco ensaios no melhor arranjo de aspersores.

Tabela 1 - Condições dos ensaios e valores do coeficiente de distribuição obtidos na determinação do espaçamento e número de aspersores

\begin{tabular}{cccccc}
\hline $\begin{array}{c}\text { Número de } \\
\text { aspersores por } \\
\text { tubo de PVC }\end{array}$ & $\begin{array}{c}\text { Distância dos } \\
\text { aspersores da } \\
\text { extremidade do tubo de } \\
\text { PVC (m) }\end{array}$ & $\begin{array}{c}\text { Bitola do } \\
\text { tubo de } \\
\text { PVC (pol.) }\end{array}$ & $\begin{array}{c}\text { Número de } \\
\text { tubos de } \\
\text { PVC }\end{array}$ & $\begin{array}{c}\text { Distância do tubo de } \\
\text { PVC da extremidade } \\
\text { do telhado (m) }\end{array}$ & $\begin{array}{c}\text { CUC } \\
(\%)\end{array}$ \\
\hline 5 & 0,2 & $3 / 4$ & 3 & 0,3 & 2,5 \\
5 & 0,2 & $3 / 4$ & 3 & 0,3 & 2,0 \\
3 & 0,2 & $3 / 4$ & 3 & 0,3 & 16,3 \\
2 & 0,3 & $3 / 4$ & 3 & 0,2 & 14,4 \\
2 & 0,3 & $3 / 4$ & 3 & 0,2 & 32,5 \\
3 & 0,2 & $3 / 4$ & 3 & 0,2 & 38,6 \\
3 & 0,2 & $1 / 2$ & 3 & 0,2 & 6,5 \\
3 & 0,2 & $1 / 2$ & 3 & 0,2 & 10,9 \\
3 & 0,2 & $1 / 2$ & 4 & 0,2 & 32,5 \\
3 & 0,2 & $3 / 4$ & 3 & 0,3 & 48,4 \\
3 & 0,2 & $3 / 4$ & 2 & 0,3 & 56,2 \\
3 & 0,3 & $3 / 4$ & 2 & 0,3 & 39,6 \\
3 & 0,3 & $3 / 4$ & 2 & 0,2 & 48,1 \\
3 & 0,3 & $3 / 4$ & 3 & 51,2 \\
\hline
\end{tabular}

64 Moruzzi, R. B.; Moura, C. C. de; Barbassa, A. P 
Tabela 2 - Estimativa do intervalo de intensidade de chuva utilizada, a partir da intensidade medida nos ensaios com água de torneira alimentada por reservatório elevado a $10 \mathrm{~m}$

\begin{tabular}{c|c}
\hline Ensaio & $\boldsymbol{I}_{\text {medido }}\left(\mathbf{m m} \cdot \mathbf{h}^{\mathbf{- 1}}\right)$ \\
\hline 1 & 117,7 \\
2 & 81,2 \\
3 & 104,5 \\
4 & 111,8 \\
5 & 102,4 \\
Desv. pad. & 13,9 \\
Int. 95\% & 12,2 \\
Média & 103,5 \\
\hline
\end{tabular}

Nota: Os valores de $I_{\text {medido }}$ foram obtidos a partir da Equação 2 e convertidos para mm. $\mathrm{h}^{-1}$.

Dessa forma, tem-se a faixa de valores para $95 \%$ de confiança: $91,3 \leq I(\mathrm{~mm} / \mathrm{h}) \leq 115,7$. Assumindo $\bar{I}$ como o $I_{\text {entrada, }}$ para todos os ensaios, tem-se lâmina total média de $51,7 \mathrm{~mm}$ para os $30 \mathrm{~min}$ de duração de cada ensaio. Utilizando a Equação (3), pode-se estimar o período de retorno equivalente dessa chuva para a cidade de Rio Claro, obtendo o valor correspondente a $T$ de 100 anos. Vale mencionar que o período de retorno obtido constitui apenas valor de referência, o qual, juntamente com o volume total precipitado, permite inferir a respeito do desempenho dos módulos. Tal resultado é influenciado pela distribuição espacial da chuva simulada, bem como pela duração do ensaio. Assim, pode-se inferir que as condições investigadas referem-se a chuvas intensas.

A variação da umidade do solo $(\Delta u)$ antes e após cada ensaio, para as diferentes inclinações, $(i)$ de $10 \%, 20 \%$ e $30 \%$, foi registrada, e seus valores podem ser observados na Tabela 3. Esses dados foram utilizados para análise de correlação com parcela armazenada.

Com exceção do primeiro ensaio, em que todos os módulos apresentavam umidade antecedente bem menor que as demais, todos os ensaios foram realizados em condições em que o solo apresentava umidade próximo à saturação (18\%). $\mathrm{O}$ valor da umidade final (posterior a cada bateria de ensaio) foi influenciado pela presença de parcela residual (água livre) no momento da coleta, razão pela qual alguns valores de umidade extrapolaram a saturação do solo.

Na Figura 3 apresenta-se o comportamento das parcelas escoadas e percoladas para os três módulos investigados em diferentes condições de umidade antecedente. Verifica-se que as parcelas escoadas sofrem menor interferência no módulo com valor de $i$ de $10 \%$, quando comparado aos demais. Para esse módulo ( $i$ de $10 \%$ ), as parcelas percoladas foram sempre muito maiores que a escoada. O mesmo não ocorre nos demais módulos ( $i$ de $20 \%$ e $30 \%$ ), para os quais a umidade antecedente influenciou mais decisivamente nas parcelas.

Ainda na Figura 3, pode-se observar que a soma das parcelas escoadas e percoladas apresenta valores médios de $77 \%$ para a inclinação de $10 \%$, e de $80 \%$ para as demais. Embora com dinâmicas distintas, pode-se considerar que as parcelas escoadas e percoladas retornam ao sistema de drenagem, caso não esteja previsto nenhum outro uso para essas parcelas.

Na Tabela 4 apresentam-se os valores de Cexp. para cada módulo em condições distintas de umidade antecedente. Com exceção do primeiro ensaio, em que o solo estava bastante seco em relação aos demais, verifica-se que o abatimento, representado pelo Cexp., foi da ordem de $1 \%$ para o módulo com inclinação de $10 \%$, e de $35 \%$ para os demais. Khan $\left(2001^{2}\right.$ apud TOMAZ, 2003) apresenta valores de coeficientes de runoff da ordem de 0,27 para telhados verdes, sem menção à inclinação ou ao período de retorno relacionado. Para superfícies descobertas, o mesmo autor apresenta coeficientes de runoff variando de 0,22 a 0,37 , para declividades de $0,5 \%$ a $5 \%$, novamente sem menção ao período de retorno associado. As parcelas armazenadas foram da ordem de 11,6 \pm 1,4 mm para o módulo com $i$ de $10 \%$, de $10,0 \pm$ 1,2 mm para o módulo com $i$ de $20 \%$, e de $9,5 \pm$ 1,1 mm para o módulo com $i$ de $30 \%$, com $95 \%$ de confiança para a média nas diferentes condições de umidade investigadas, corroborando os resultados apresentados por Persch, Tassi e Allasia (2012), os quais obtiveram valores de armazenamento da ordem de $14 \mathrm{~mm}$. Fica evidente, portanto, que o módulo com menor inclinação é capaz de reter maiores valores de precipitação, quando comparados aos demais. Embora esses resultados já eram esperados, destaca-se a importância do

\footnotetext{
${ }^{2}$ KHAN. Domestic Roof Water Harvesting in Thar Desert. In: NATIONAL SEMINAR ON GROUNDWATER MANAGEMENT STRATEGIES IN ARID AND SEMI ARID REGIONS, Jaipur, 2001 Proceedings... Jaipur: Groundwater Department, Government of Rajasthan, 2001.
} 
parâmetro inclinação quando se deseja reter parcela da precipitação. Tem sido recorrente a instalação de telhados verdes extensivos, por meio da montagem desse sistema sobre a cobertura convencional de telhas cerâmicas (valores de $i$ de até 30\%). Nesses casos, a capacidade de retenção dessas estruturas é limitada em relação aos sistemas que foram concebidos para a finalidade específica de retenção de água pluvial, os quais devem possuir menores valores de inclinação quando comparados a telhados concebidos para coberturas convencionais.

$\mathrm{Na}$ Tabela 4, fica evidente, portanto, que a umidade antecedente e a inclinação do telhado são fatores decisivos para o desempenho no que tange à retenção da água no telhado verde, a qual pode ser estimada por meio do quociente entre $(1-R A) \mathrm{e}$ a precipitação total. Tal quociente permite a análise da retenção de água na camada do solo.

Tabela 3 - Cálculo do $\Delta \mathrm{u}$, com base na diferença entre umidade posterior e antecedente. Os dados foram colhidos no aparelho da Solotest, para cada ensaio realizado nos módulos com inclinações de $10 \%, 20 \%$ e $30 \%$

\begin{tabular}{c|c|c|r}
\hline Módulos piloto & Umidade antecedente (\%) & Umidade posterior $(\boldsymbol{\%})$ & $\boldsymbol{\Delta u}$ \\
\hline \multirow{3}{*}{ i10\% } & 1,1 & 18,8 & $\mathbf{1 7 , 7}$ \\
& 18,4 & 20,4 & $\mathbf{2 , 0}$ \\
& 18,0 & 20,8 & $\mathbf{2 , 8}$ \\
& 19,6 & 24,0 & $\mathbf{4 , 4}$ \\
\multirow{2}{*}{$20 \%$} & 21,2 & 28,8 & $\mathbf{7 , 6}$ \\
\hline \multirow{3}{*}{$\mathrm{i} 30 \%$} & 1,1 & 17,6 & $\mathbf{1 6 , 5}$ \\
& 15,2 & 19,6 & $\mathbf{4 , 4}$ \\
& 12,4 & 13,6 & $\mathbf{1 , 2}$ \\
& 17,2 & 20,4 & $\mathbf{3 , 2}$ \\
& 18,4 & 26,0 & $\mathbf{7 , 6}$ \\
\hline & 1,1 & 20,1 & $\mathbf{1 9 , 0}$ \\
& 19,6 & 20,4 & $\mathbf{0 , 8}$ \\
& 13,6 & 14,4 & $\mathbf{0 , 8}$ \\
& 16,0 & 18,8 & $\mathbf{2 , 8}$ \\
\hline
\end{tabular}

Figura 3 - Lâminas escoadas e percoladas para diferentes condições de umidade antecedente e inclinações (i) de $10 \%, 20 \%$ e $30 \%$

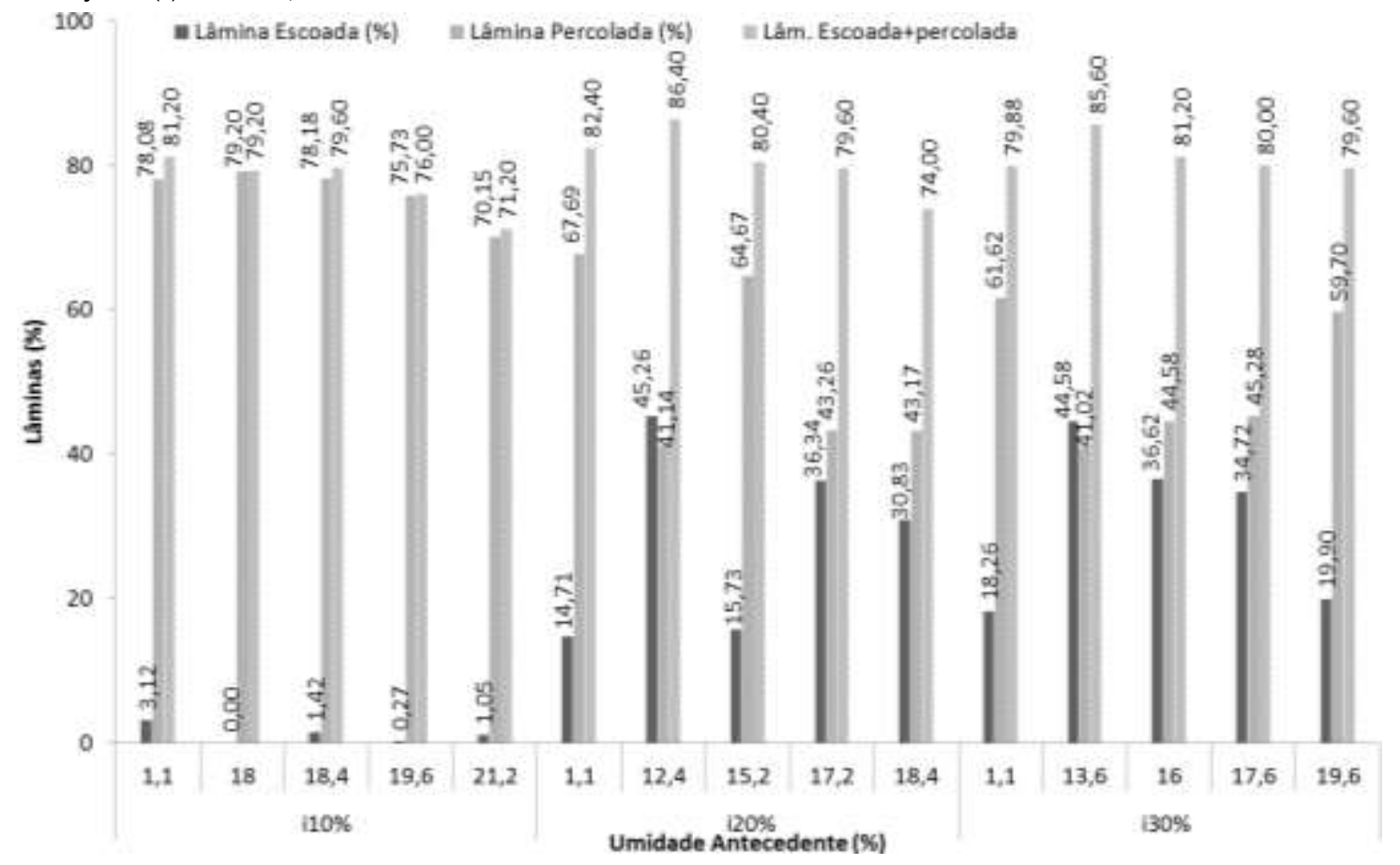

66 Moruzzi, R. B.; Moura, C. C. de; Barbassa, A. P 
Tabela 4 - Coeficiente de escoamento superficial experimental (Cexp.) para cada umidade antecedente e valor de $\Delta u$ nos três módulos investigados, com inclinações de $10 \%, 20 \%$ e $30 \%$

\begin{tabular}{|c|c|c|c|c|c|}
\hline $\begin{array}{c}\text { Umidade } \\
\text { inicial }(\%)\end{array}$ & $\Delta U$ & $\begin{array}{c}\text { Lâmina } \\
\text { escoada } \\
(\mathbf{m m})\end{array}$ & $\begin{array}{l}\text { Prec. total } \\
\quad(\mathrm{mm})\end{array}$ & $(\text { Cexp. })^{* *}$ & $\begin{array}{c}R A \\
\mathrm{~mm} \operatorname{arm} / \mathbf{m}^{2} *\end{array}$ \\
\hline \multicolumn{6}{|l|}{$\mathrm{i}=10 \%$} \\
\hline 1,1 & 17,7 & 0,8 & 51,8 & $1,6 \%$ & $9,7 \pm 1,4$ \\
\hline 18,0 & 2,8 & 0,0 & 51,8 & $0,0 \%$ & $10,1 \pm 1,4$ \\
\hline 18,4 & 2,0 & 1,0 & 51,8 & $1,9 \%$ & $10,711 \pm 1,4$ \\
\hline 19,6 & 4,4 & 0,2 & 51,8 & $0,4 \%$ & $12,4 \pm 1,4$ \\
\hline 21,2 & 7,6 & 0,9 & 51,8 & $1,7 \%$ & $14,8 \pm 1,4$ \\
\hline \multicolumn{6}{|l|}{$\mathrm{i}=20 \%$} \\
\hline 1,1 & 16,5 & 5,0 & 51,8 & $9,7 \%$ & $9,0 \pm 1,2$ \\
\hline 12,4 & 1,2 & 22,0 & 51,8 & $42,5 \%$ & $10,0 \pm 1,2$ \\
\hline 15,2 & 4,4 & 9,0 & 51,8 & $17,4 \%$ & $7,0 \pm 1,2$ \\
\hline 17,2 & 3,2 & 21,0 & 51,8 & $40,6 \%$ & $10,5 \pm 1,2$ \\
\hline 18,4 & 7,6 & 20,0 & 51,8 & $38,7 \%$ & $13,4 \pm 1,2$ \\
\hline \multicolumn{6}{|l|}{$\mathrm{i}=30 \%$} \\
\hline 1,1 & 19,0 & 8,0 & 51,8 & $15,5 \%$ & $10,4 \pm 1,1$ \\
\hline 13,6 & 0,8 & 25,0 & 51,8 & $48,3 \%$ & $10,5 \pm 1,1$ \\
\hline 16 & 2,8 & 23,0 & 51,8 & $44,4 \%$ & $7,4 \pm 1,1$ \\
\hline 17,6 & 2,4 & 23,0 & 51,8 & $44,4 \%$ & $9,7 \pm 1,1$ \\
\hline 19,6 & 0,8 & 11,0 & 51,8 & $21,3 \%$ & $10,3 \pm 1,1$ \\
\hline
\end{tabular}

Nota: *mm de precipitação armazenada por unidade de área; ${ }^{* *}$ quantificado em relação à lâmina escoada em superfície.

A avaliação do comportamento dessas variáveis com as parcelas escoadas e armazenadas foram avaliadas por meio de regressão multilinear, para os resultados obtidos neste estudo. Os valores de $\mathrm{R}^{2}$-Ajustado foram sempre maiores que os obtidos pela regressão utilizando somente uma das variáveis $\left(\mathrm{R}^{2}\right)$, o que sugere uma melhor explicação das curvas quando as variáveis foram combinadas. Para a parcela armazenada, o valor de $\mathrm{R}^{2}$ obtido foi de 0,75 para uma variável, e o de $\mathrm{R}^{2}$ Ajustado foi de 0,87 , enquanto, para a parcela escoada, esses valores alteraram-se de 0,66 para 0,81 , respectivamente para $R^{2}$ e $R^{2}$-Ajustado. As Equações 4 e 5 apresentam as relações de umidade $(\Delta u)$ e inclinação $(i)$ para as parcelas armazenada e escoada respectivamente. Nas Figuras 4 e 5 foram plotados os valores calculados versus os resultados experimentais, juntamente com as retas de ajuste perfeito (1:1), e o valor de $\mathrm{R}^{2}$ correspondente ao ajuste linear dos pontos experimentais. Verifica-se que, para os dois casos, a reta ajustada se aproxima da reta de ajuste perfeito $(1: 1)$, correspondente à função $f(x)=x$. Os resíduos padronizados para as duas regressões multilineares foram plotados em função dos valores previstos de parcelas (Figura 6). Verifica-se uma distribuição uniforme dos resíduos, o que corrobora a boa representatividade da equação empírica obtida. Para a Equação 4, pode-se verificar a relação inversa entre parcela armazenada e inclinação $(i)$, e direta para $\Delta u$. Os resultados indicam também a relação direta para parcela escoada e inclinação $(i)$, e inversa para o valor de $\Delta u$, no caso da Equação 5.

$$
\begin{array}{ll}
\text { Lam } \operatorname{arm}(\%)=-104,97 .(i)+1,74 .(\Delta u)+32,01 & \text { Eq. } 4 \\
\text { Lam esc }(\%)=155,43 .(i)-1,08 .(\Delta u)-2,75 & \text { Eq. } 5
\end{array}
$$

Em suma, pode-se inferir que, como estrutura de retenção e detenção, o telhado verde desempenha um papel na atenuação de parte da precipitação total. Sua efetividade, entretanto, está diretamente relacionada à inclinação da superfície, a qual determina sua capacidade de estocagem, bem como a característica física do solo e sua umidade, as quais são determinantes na capacidade de acondicionamento de água nos vazios intersticiais.

No que tange à qualidade da água que passa pelo telhado, foram medidos os valores de turbidez e cor aparente em todas as baterias de ensaios realizados para as parcelas percoladas e escoadas. Nas Figuras 7 e 8 são apresentados os valores de cada parâmetro monitorado para as parcelas escoadas e percoladas respectivamente. Na Tabela 5 pode-se observar a correlação entre as parcelas escoadas e percoladas e seus respectivos valores de cor aparente e turbidez. Vale mencionar que esses parâmetros de qualidade não foram avaliados para as parcelas armazenadas. Observam-se claramente as correlações inversas obtidas para a maioria das medidas, indicando que maiores valores de parcelas incorrem em menores valores de cor aparente e turbidez. 
Evidentemente, o volume de cada parcela escoada e percolada (expresso em parcelas) interfere nas medidas de cor aparente e turbidez, uma vez que, transcorrido o tempo inicial, após os primeiros milímetros de chuva, o material transportado em suspensão e dissolvido tende a estabilizar. Esse efeito conduz à diluição dos efluentes (escoados e percolados), devido à introdução de volumes com menor concentração de material em suspensão e dissolvido. Assim, a avaliação do material transportado não pode ser verificada diretamente.

Figura 4 - Parcelas armazenadas calculadas e medidas em relação à inclinação e à umidade antecedente para todos os ensaios realizados nos módulos piloto de telhado verde extensivo

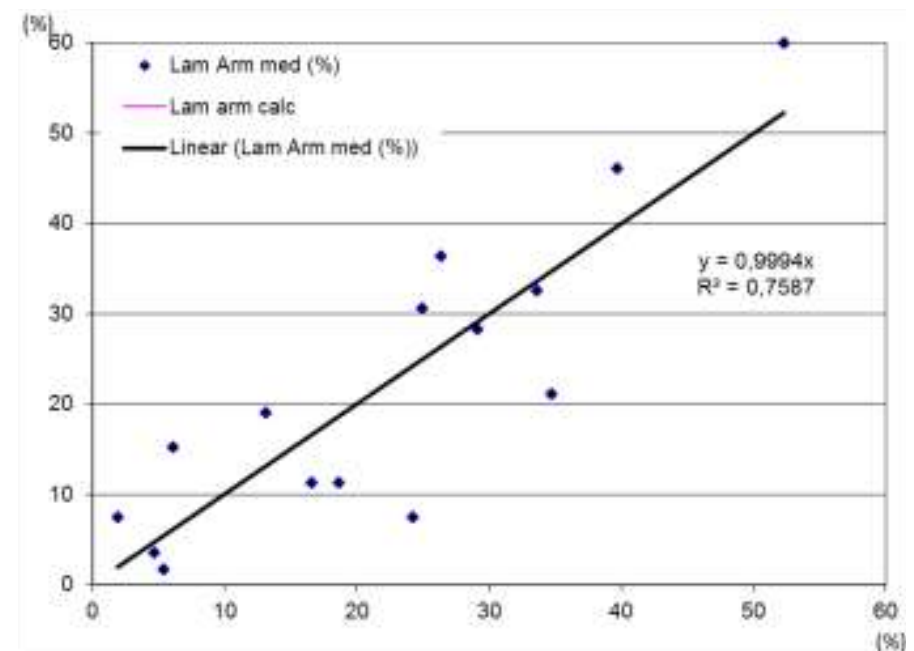

Nota: Legenda:

Lam Arm med = parcela armazenada medida;

Lam arm calc = parcela armazenada calculada por regressão, segundo a equação de regressão multilinear (Equação 3); e

Linear (Lam Arm med) = regressão linear dos valores de parcela armazenada medida nos ensaios com os três módulos piloto.

Figura 5 - Parcelas escoadas calculadas e medidas em relação à inclinação e à umidade antecedente para todos os ensaios realizados nos módulos piloto de telhado verde extensivo

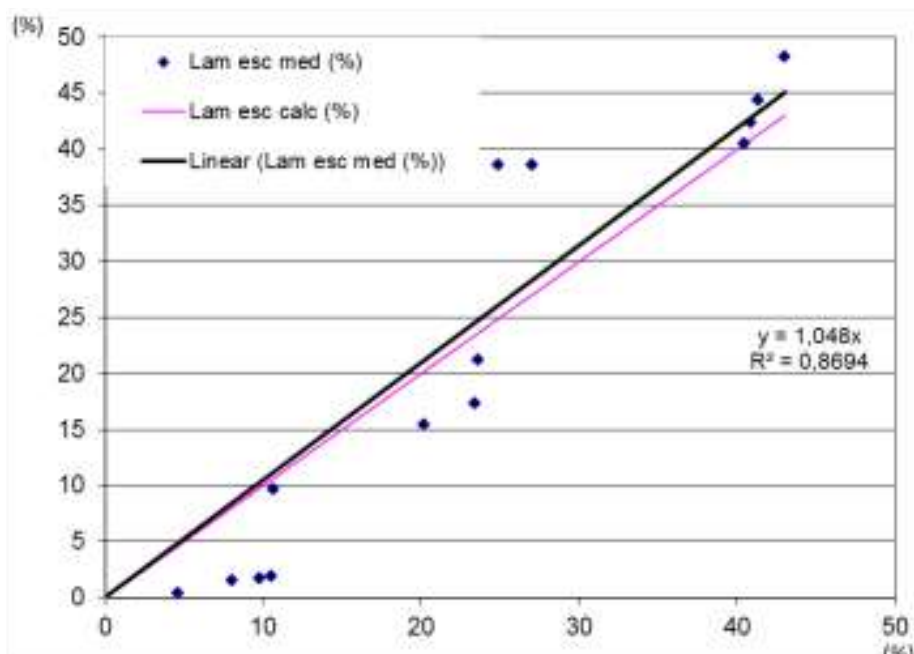

Nota: Legenda:

Lam esc med = parcela escoada medida;

Lam esc calc = parcela escoada calculada por regressão, segundo a equação de regressão multilinear (Equação 4); e

Linear $($ Lam esc med) = regressão linear dos valores de parcela escoada medida nos ensaios com os três módulos piloto.

68 Moruzzi, R. B.; Moura, C. C. de; Barbassa, A. P 
Figura 6 - Distribuição dos resíduos padronizados para as duas regressões multilineares em função dos valores previstos de parcelas escoadas e armazenadas

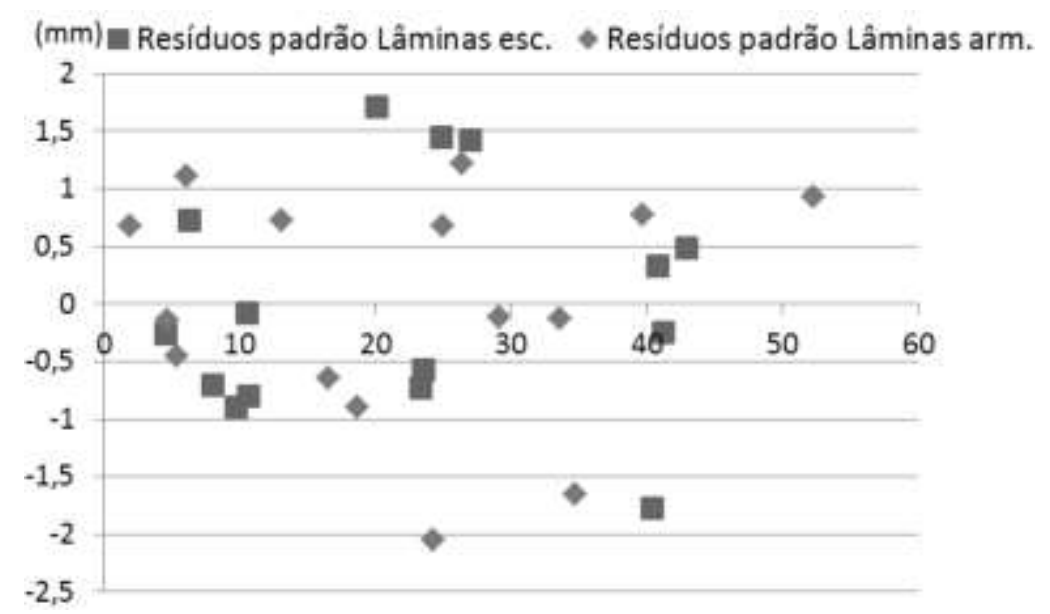

Figura 7 - Cor aparente e turbidez da água escoada para as inclinações de $10 \%, 20 \%$ e $30 \%$

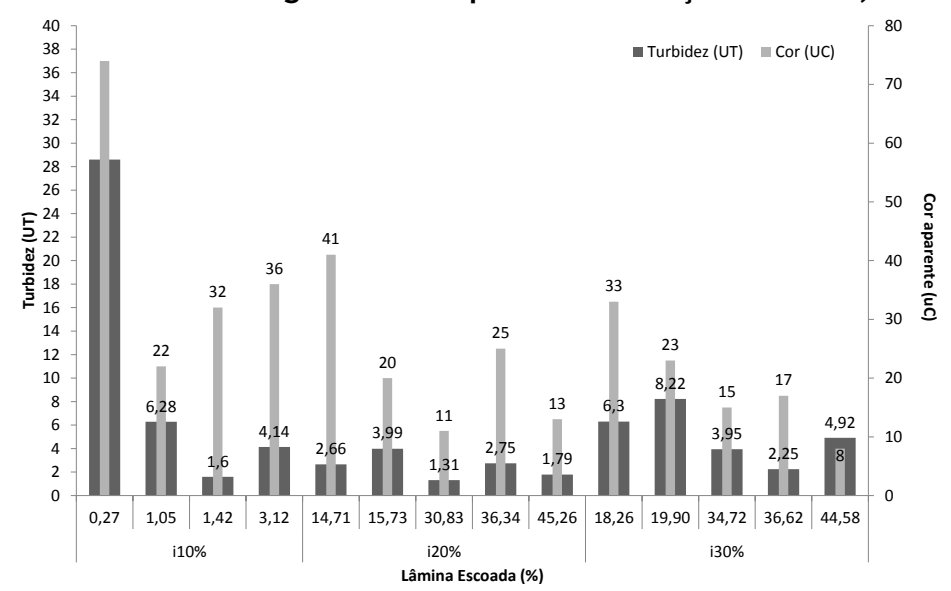

Figura 8 - Cor aparente e turbidez da água percolada para as inclinações de $10 \%, 20 \%$ e $30 \%$

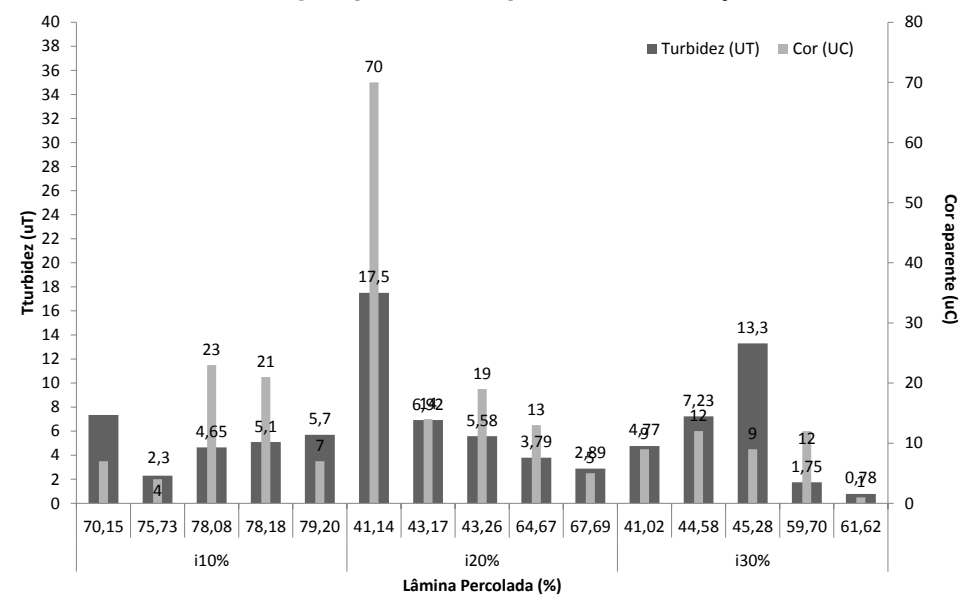


Tabela 5 - Correlação entre os valores de parcelas escoadas e percoladas e os parâmetros de cor aparente e turbidez para os três módulos piloto investigados, para diferentes valores de inclinação (i), correspondentes a $10 \%, 20 \%$ e $30 \%$

\begin{tabular}{cc}
\hline & Parcela Escoada (\%) \\
\hline Parcela Escoada (\%) & $10 \%$ \\
Turbidez - escoada & 1,0 \\
Cor - escoada & $-0,3$ \\
\hline & 0,1 \\
\hline Parcela Escoada (\%) & $20 \%$ \\
Turbidez - escoada & 1,0 \\
Cor - escoada & $-0,6$ \\
\hline & $-0,6$ \\
\hline Parcela Escoada (\%) & $30 \%$ \\
Turbidez - escoada & 1,0 \\
Cor - escoada & $-0,7$ \\
\hline & $-0,9$ \\
\hline & Parcela Percolada (\%) \\
\hline Parcela Percolada (\%) & $10 \%$ \\
turbidez - percolada & 1,0 \\
cor - percolada & $-0,4$ \\
\hline & 0,4 \\
\hline Parcela Percolada (\%) & $20 \%$ \\
turbidez - percolada & 1,0 \\
cor - percolada & $-0,7$ \\
\hline Parcela Percolada (\%) & $-0,6$ \\
turbidez - percolada & $30 \%$ \\
cor - percolada & 1,0 \\
\hline
\end{tabular}

Entretanto, ao multiplicar as parcelas pelo valor de turbidez ou pelo valor de cor aparente, pode-se inferir indiretamente sobre a massa de material suspenso ou dissolvido transportado por unidade de área, de forma a permitir a avaliação da tendência de material transportado para cada parcela escoada e percolada em cada um dos módulos estudados. Esse número $(N)$, o qual reflete de forma indireta as grandezas de massa/área, pode também ser parametrizado em função do maior valor observado. Nas Figuras 9 e 10, são apresentados os valores de $N$ para o parâmetro cor aparente $(N C)$ e para o parâmetro turbidez $(N T)$, para as parcelas escoadas e percoladas, nas baterias de ensaios realizadas com os três módulos investigados.

Por meio da análise da Figura 9, pode-se verificar que o valor de $N T$ e $N C$ tendem a crescer com o aumento das parcelas escoadas e com o aumento da inclinação (i) de cada módulo investigado. Nessas condições, pode-se inferir indiretamente que a massa de material transportado por unidade de área no telhado verde aumenta. Cabe salientar que o parâmetro cor aparente sofre interferência também do material particulado, sendo a cor verdadeira causada somente por material dissolvido. Ao contrário, constata-se na Figura 10 que os valores de $N T$ e $N C$ tendem a diminuir com o aumento das parcelas percoladas, sugerindo um efeito de filtro do meio granular. Vale mencionar que esses parâmetros constituem medidas indiretas, em situações parametrizadas, em que se buscou uma análise de tendência, e não de desempenho dos sistemas, e sua eficiência na remoção de poluentes. Para uma análise pormenorizada, mais ensaios devem ser conduzidos, e seus resultados ponderados à luz dos fenômenos que governam o transporte e a aderência de material particulado em meio granular. Todavia, verifica-se claramente que a inclinação tem relação direta com a quantidade de material transportado pela superfície do telhado, medido indiretamente pela turbidez. Em relação à cor aparente, a água higroscópica provavelmente interfere na transferência de soluto, minimizando o contato entre água percolada e material particulado. 
Figura 9 - Valores do número $(N)$ [massa/área] parametrizado em função do maior valor de $N$ observado, para as parcelas escoadas, nas baterias de ensaios realizadas com os três módulos investigados

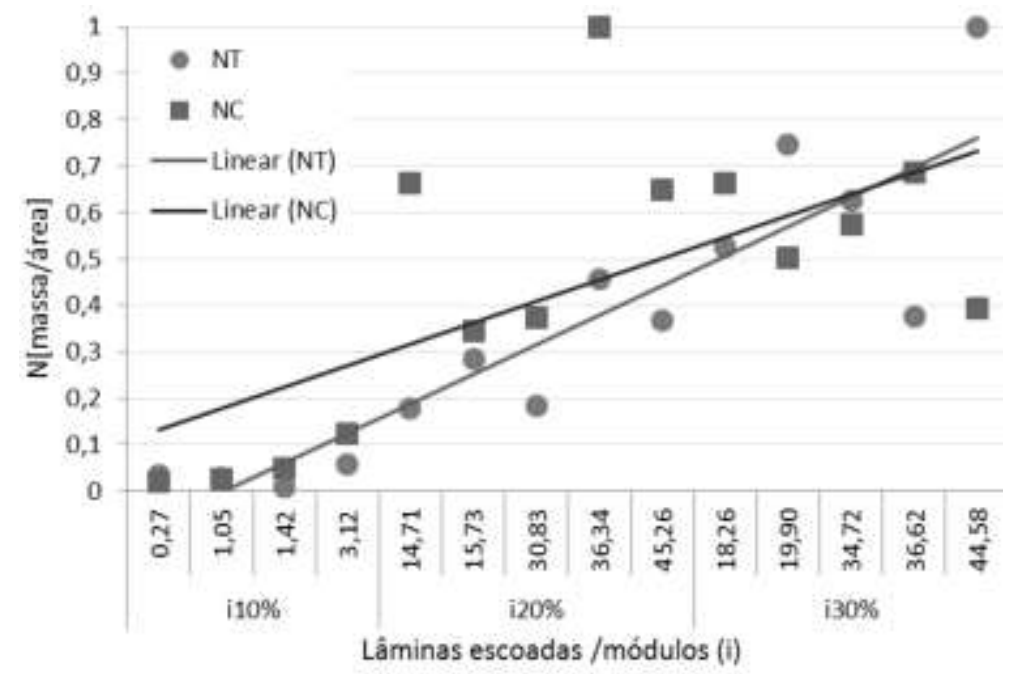

Nota: Legenda:

(NC) representa o valor de $N$ para o parâmetro cor aparente; e

(NT) representa o valor de $N$ para o parâmetro turbidez.

Figura 10 - Valores do número $(N)$ [massa/área] parametrizado em função do maior valor de $N$ observado, para as parcelas percoladas, nas baterias de ensaios realizadas com os três módulos investigados

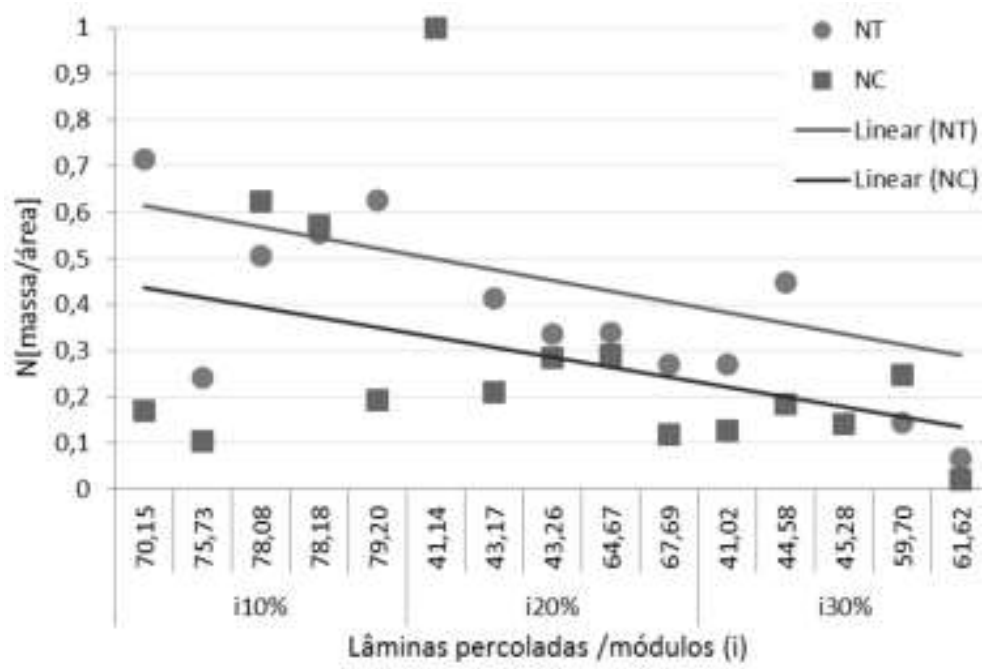

Nota: Legenda:

(NC) representa o valor de $N$ para o parâmetro cor aparente; e

(NT) representa o valor de $N$ para o parâmetro turbidez.

\section{Conclusões}

Este trabalho investigou o efeito da inclinação e da umidade antecedente do solo nas parcelas escoadas, armazenadas e percoladas em telhados verdes extensivos construídos em escala piloto e seus efeitos na quantidade e na qualidade para chuvas recorrentes e consecutivas. Os resultados demonstraram que, para valores de $i=10 \%$, os menores valores de Cexp. foram registrados (média de $1,01 \% \pm 0,7 \%$ para $95 \%$ de confiança). Para valor de $i=20 \%$, o valor de Cexp. médio foi de $34,7 \% \pm 13,2 \%$, e para valor de $i=30 \%$, o valor de Cexp. foi de $39 \% \pm 15,2 \%$, ambos para $95 \%$ de confiança. A soma das parcelas escoadas e percoladas apresentam valores médios de $77 \%$ para a inclinação de $10 \%$, e de $80 \%$ para as demais. As lâminas armazenadas foram da ordem 
de 11,6 $\pm 1,4 \mathrm{~mm}$ para o módulo com $i$ de $10 \%$, de $10,0 \pm 1,2 \mathrm{~mm}$ para o módulo com $i$ de $20 \%$, e de $9,5 \pm 1,1 \mathrm{~mm}$ para o módulo com $i$ de $30 \%$, com 95\% de confiança para a média nas diferentes condições de umidade investigadas. A regressão multilinear para os parâmetros $i$ e $\Delta U$ obteve coeficiente de explicação de $87 \%$ para parcela armazenada e de $81 \%$ para parcela escoada $\left(\mathrm{R}^{2}\right.$ Ajustado). As equações finais obtidas indicam a relação inversa entre parcela armazenada e inclinação $(i)$, e direta para $\Delta u$. Para parcelas escoadas, os resultados indicam a relação direta para parcela escoada e inclinação $(i)$, e inversa para o valor de $\Delta u$. A análise de $N$ permitiu verificar maiores tendências de material transportado à medida que $i$ e $\Delta U$ aumentam. Para parcelas percoladas, a tendência inversa foi observada. Os resultados indicaram que a inclinação e a umidade antecedente são decisivas tanto na redução do escoamento gerado quanto no transporte de material do telhado para o sistema de drenagem.

\section{Referências}

BARRIO, E. P. D. Analysis of the Green Roofs Cooling Potential in Buildings. Energy and Buildings, Issy les Moulineaux, v. 27, p. 179-193, 1997.

BASS, B. et al. Mitigating the Urban Heat Island With Green Roof Infrastructure. Departament of Earth and Oceans Sciences. University of British Columbia. 2000. Disponível em:

<http://www.cleanairpartnership.org/cooltoronto/p df/finalpaper_bass.pdf $>$. Acesso em: 13 ago. 2014.

\section{EMPRESA BRASILEIRA DE PESQUISA}

AGROPECUÁRIA. Manual de Métodos de

Análise de Solo. Centro Nacional de Pesquisa de Solos. EMBRAPA. Rio de Janeiro, 1997.

Disponível em:

<http://ag20.cnptia.embrapa.br/Repositorio/Manua 1\%20de\%20MetodosID-6trBnpFBp8.pdf>.

Acesso: 13 ago. 2014.

FERREIRA, C. A.; MORUZZI, R. B. Considerações Sobre a Aplicação do Telhado Verde Para Captação de Água de Chuva em Sistemas de Aproveitamento Para Fins Não Potáveis. In: ENCONTRO NACIONAL, 4.; ENCONTRO LATINO AMERICANO SOBRE EDIFICAÇÕES E COMUNIDADES SUSTENTÁVEIS, 2., São Paulo, 2007. Anais... São Paulo, 2007.
GETTER, K. L.; ROWE, D. B.; ANDRESEN, J. A. Quantifying the Effect of Slope on Extensive Green Roof Storm Water Retention. Ecological Engineering, v. 31. N. 4, p. 225-231, 2007.

\section{INTERNATIONAL GREEN ROOF}

\section{ASSOCIATION. Global Networking for Green}

Roofs. Disponível em: <http://www.igraworld.com/index.php>. Acesso em: 17 maio 2010.

KÖHLER, M. et al. Urban Water Retention by Greened Roofs in Temperate and Tropical Climate. In: INTERNATIONAL FEDERATION OF LANDSCAPE ARCHITECTS, 38., Singapore, 2001. Proceedings... Singapore, 2001.

KOLB, W. Telhados de Cobertura Verde e Manejo de Águas Pluviais. In: SIMPÓSIO CAPTAÇÃO E MANEJO DE ÁGUA DE CHUVA, 4., Juazeiro, 2003. Anais... Juazeiro, 2003.

LAZZARIN, R. M.; CASTELLOTTI, F.;

BUSATO, F. Experimental Measurements and Numerical Modeling of a Green Roof. Energy and Buildings, Milan, v. 37, p. 1260-1267, 2005.

LORENZINI NETO, F. et al. Calibração e Simulação Hidrológica de Um Telhado Verde Utilizando o Método da Curva-Número do SCS. In: SIMPÓSIO BRASILEIRO DE RECURSOS HÍDRICOS, 20., Bento Gonçalves, 2013. Anais... Bento Gonçalves, 2013.

MENTENS, J.; RAES, D.; HERMY, M. Green Roofs as a Tool For Solving the Rainwater Runoff Problem in the Urbanized 21st Century?

Landscape and Urban Planning, Leuven, v. 77, n. 3, p. 217-226, 2005.

MORAN, A.; HUNT, B.; JENNINGS, G. A North Carolina Field Study to Evaluate Greenroof Runoff Quantity, Runoff Quality, and Plant Growth. North Carolina, 2004. Ms. (Biological and Agricultural Engineering) - North Carolina State University, North Carolina, 2004.

MORUZZI, R. B.; OLIVEIRA, S. C. de. Relação Entre Intensidade, Duração e Frequência de Chuvas em Rio Claro, SP: métodos e aplicação.

Revista Teoria e Prática na Engenharia Civil, v. 9, n. 13, p. 59-68, maio 2009.

OHNUMA JUNIOR, A. A.; HALASZ, M. R. T.; MENDIONDO, E. M. Monitoramento das Águas Subsuperficiais em Telhados Verdes Como Medida Sustentável de Combate a Poluição Hídrica. In: ENCONTRO NACIONAL, 6.; ENCONTRO LATINO-AMERICANO SOBRE EDIFICAÇÕES E COMUNIDADES SUSTENTÁVEIS, 4., Vitória, 2011. Anais... Vitória, 2011. 
PERSCH, C. G.; TASSI, R.; ALLASIA, D. G. Avaliação do Comportamento de Um Telhado Verde no Controle Quantitativo do Escoamento Pluvial a Partir de Um Modelo de Balanço de Volumes de Longo Prazo. In: Encontro Nacional de Águas Urbanas, 9., Belo Horizonte, 2012.

Anais... Belo Horizonte, 2012.

PORTOLANO, M. G. A Ecologia na

Arquitetura: teto jardim. Rio Claro, 2007. $65 \mathrm{f}$. Trabalho de Conclusão de Curso (Graduação em Ecologia) - Instituto de Biociências, Universidade Estadual Paulista, Rio Claro, 2007.

ROBERTSON, S. Stanford University's Green Dorm Water System Management Project. Stanford, Califórnia, 2005. Disponível em: <http://sustainability.stanford.edu/greendorm/ involvement/coursework/CEE179_exterior_LEPfi nalReport.doc>. Acesso em: 14 ago. 2014.

\section{RODRIGUEZ, R. The History of Green Roof}

Technology. 2006. Disponível em: <http://www. ifenergy.com/50226711/the_history_of_green_roo f_technology.php>. Acesso em: 14 ago. 2014.
SILVA, G. B. L. et al. A. Influência de Aspectos Construtivos e de Uso na Eficiência de Revestimentos Com Superfícies Permeáveis. Revista Brasileira de Recursos Hídricos, v. 14, n. 1, p. 123-134, jan./mar. 2009.

TEEMUSK, A.; MANDER, U. Rainwater Runoff Quantity and Quality Performance From a Greenroof: the effects of short-term events. Ecological Engineering, v. 30, p. 271-277, 2007.

TOMAZ, P. Aproveitamento de Água de Chuva Para Áreas Urbanas e Fins Não Potáveis. São Paulo: Navegar Editora MF, 2003.

YANG, J.; YU, Q.; GONG, P. Quantifying air pollution removal by green roofs in Chicago. Atmospheric Environment, Chicago, v. 42, p. 7266-7273, 2008.

\section{Agradecimentos}

Os autores agradecem à Finep, pela concessão de bolsa na modalidade de iniciação científica (IC) referente ao projeto pertencente ao Edital MCT/FINEP/CT-Hidro Processos Hidráulicos 02/2007, Referência 2198/07, em parceria com a UFSCar e a Unesp.

\footnotetext{
Rodrigo Braga Moruzzi

Departamento de Planejamento Regional, Instituto de Geociências e Ciências Exatas de Rio Claro | Universidade Estadual Paulista Júlio de Mesquita Filho | Avenida 24 A, 1515, Bela Vista | Rio Claro - SP - Brasil | CEP 13506-900 | Tel.: (19) 3526-9339 | E-mail: rmoruzzi@rc.unesp.br

\section{Cinthia Cristine de Moura}

Centro de Estudos Ambientais. Universidade Estadual Paulista Júlio de Mesquita Filho | Tel. (19) 3526-9482 | E-mail: cinthia.mr@gmail.com

Ademir Pacelli Barbassa

Departemento de Engenharia Civil | Universidade Federal de São Carlos | Rod. Washington Luis, km 235 | São Carlos - SP - Brasil | CEP:13565-905 | Tel. (16) 3351-9306 | E-mail: barbassa@ufscar.br
}

\section{Revista Ambiente Construído}

Associação Nacional de Tecnologia do Ambiente Construído

Av. Osvaldo Aranha, $99-3^{\circ}$ andar, Centro

Porto Alegre - RS - Brasil

CEP 90035-190

Telefone: +55 (51) 3308-4084

Fax: +55 (51) 3308-4054

www.seer.ufrgs.br/ambienteconstruido

E-mail: ambienteconstruido@ufrgs.br 